\title{
Ram Horn-Shaped Inspired Folded Compact Antenna for 4G LTE-A and WLAN Portable Mobile Applications
}

\author{
Jeremiah O. Abolade $\mathbb{D}^{1}$ and Dominic B. O. Konditi ${ }^{2}$ \\ ${ }^{1}$ Department of Electrical Engineering, Pan African University, Institute for Basic Sciences, Technology and Innovation, \\ Nairobi, Kenya \\ ${ }^{2}$ School of Electrical and Electronic Engineering, The Technical University of Kenya, Nairobi, Kenya \\ Correspondence should be addressed to Jeremiah O. Abolade; aboladejeremiah@yahoo.com
}

Received 28 May 2021; Revised 7 July 2021; Accepted 2 November 2021; Published 18 November 2021

Academic Editor: Yuan Yao

Copyright (C) 2021 Jeremiah O. Abolade and Dominic B. O. Konditi. This is an open access article distributed under the Creative Commons Attribution License, which permits unrestricted use, distribution, and reproduction in any medium, provided the original work is properly cited.

\begin{abstract}
A compact dual-band ram horn-like folded antenna is presented in this work. The antenna is based on a ram horn-like folded strip, asymmetric microstrip feeding (AMF) technique, partial ground, and protruding stub at the ground plane. The dimension of the proposed antenna is $0.11 \lambda_{g} \times 0.17 \lambda_{g}$ at $2.3 \mathrm{GHz}\left(10 \times 15 \mathrm{~mm}^{2}\right)$. The proposed shape is achieved through the combination of two circular arcs with different radii. The antenna operates at $2.3 \mathrm{GHz}$ and $5.8 \mathrm{GHz}$ with a measured bandwidth of $100 \mathrm{MHz}$ and $820 \mathrm{MHz}$, a gain of $0.62 \mathrm{dBi}$ and $2.2 \mathrm{dBi}$, and radiation efficiency of $93.67 \%$ and $99.87 \%$, respectively. The prototype of the proposed antenna is fabricated and measured. The measured result shows a good agreement with the simulated result. The parametric study of the proposed antenna is performed and results are presented. Besides, a comparative study between the antennas proposed in this work and the state of the art is performed and presented. The proposed antenna is comparatively small in size than all the recently reported works in the literature while ensuring good radiation characteristics. Therefore, the antenna proposed in this work is a better candidate for future portable sub-6GHz fifth-generation (5G), Advance Long-term Evolution (LTE-A), Worldwide Interoperability for Microwave Access (WiMAX), and Wireless Local Area Network (WLAN) applications.
\end{abstract}

\section{Introduction}

The compact multiband antenna has become the darling of the wireless communication community because of the need for miniaturized devices on the part of both the manufacturers and users [1-4]. Many microwave system researchers have invested effort in realizing compact antennas such as [5-10]. Techniques such as meandering, slotting, slitting, shorting pin/plate, lumped elements, and metamaterial/ metasurface [11-15] have been exploited. The main goal of slotting, slitting, shorting pin/plate, and lumped element techniques is to make the antenna effective length longer than its physical length [16-18]. However, the meandering technique ensures maxima use of the antenna space [19]. For example, authors in [9] used a meandering strip and shorting pin to achieve a compact antenna $\left(36 \times 15 \mathrm{~mm}^{2}\right)$ operating at $2.4 \mathrm{GHz}$. The same meandering technique has been recently exploited by authors in [5-8]. Furthermore, the slotting technique has been used by authors in $[2,20-25]$. For example, authors in [20] used the Audi logo-shaped as a slot on a rectangular patch on a $20 \times 12 \mathrm{~mm}^{2}$ FR-4 substrate to achieve a triband antenna operating at $3.9 \mathrm{GHz}, 5.0 \mathrm{GHz}$, and $7.1 \mathrm{GHz}$, respectively. Also, authors in [22] use circular nested square slots comparative to an ancient coins symbol in China. The radiating patch was etched on an $88.5 \times 60 \mathrm{~mm}^{2}$ FR-4 substrate and the operating frequencies of the antenna are $1.6 \mathrm{GHz}, 2.6 \mathrm{GHz}, 3.7 \mathrm{GHz}$, and $5.3 \mathrm{GHz}$. In addition, authors in [14] reported the use of metamaterial for the antenna miniaturization. The authors used a double negative metamaterial based on the rectangular split ring resonator as the slot on the ground plane of the proposed antenna to achieve a $50 \%$ miniaturization. In the same light, authors in [15] have also used metasurface to achieve $67 \%$ miniaturization. In recent times, folded monopole antenna 
has attracted antenna design engineers due to its ability to reduce overall antenna size [25-34]. Folded monopole antenna uses the principle of space filling to miniaturize the antenna radiating patch. For example, authors in [34] proposed three folded-rectangular strip branches radiating patch etched on a $20 \times 18 \mathrm{~mm}^{2}$ FR-4 substrate.

$2.3 \mathrm{GHz}$ band is one of the most useful communication bands. It was designated International Mobile Telecommunication (IMT) by the ITU. Even though it was originally used for WiMAX applications, it has been generally adopted for the deployment of $4 \mathrm{G}$ LTE applications. This band has also been proposed for sub-6 GHz $5 \mathrm{G}$ communication deployment due to its large TDD band spectrum, good propagation behavior, and provision of better capacity. For example, Singtel Optus, STC, and Telkom in Australia, Saudi Arabia, and South Africa, respectively, are performing 5G trials in this band. In the same light, the $5 \mathrm{GHz}$ band is also one of the commonly used bands in wireless communication such as the $5 \mathrm{GHz}$ band WLAN and ISM. Therefore, the miniaturization of the antenna operating in these bands is of importance for future communication.

Therefore, in this work, an ultracompact ram horn-like folded dual-band antenna is proposed. The proposed antenna is fed with a $50 \Omega$ asymmetric microstrip feedline. The contribution of this work is the proposal of an ultracompact dual-band antenna suitable for LTE and WLAN applications compared to the recently published works in the open literature.

The remaining section of this paper is divided as follows. The detailed design and analysis of the proposed antenna are presented in Section 2. The results and discussion, which includes $S_{11}$, a parametric study of some design parameters, radiation pattern, gain, and efficiency, are presented in Section 3. The proposed antenna is compared with the recently published works in the literature and presented in Section 4, and the conclusion is presented in Section 5.

\section{Antenna Design and Analysis}

The radiating patch of the proposed antenna is a strip folded in a ram horn-like shape, fed with a $50 \Omega$ asymmetric microstrip feedline, and a partial ground with a protruding stub made up the ground plane, as shown in Figure 1. The ram horn-like shape is realized through the concatenation of two slit rings, as shown in Figure 1(c). The antenna is built on a $10 \times 15 \mathrm{~mm}^{2}$ duroid5880 substrate of $1.57 \mathrm{~mm}$ thickness. The detailed configuration is given in Figure 1, and the optimized parameters are given in Table 1 . The distance between the edge of the radiating patch and the substrate is $1 \mathrm{~mm}$ at the two sides and $0.75 \mathrm{~mm}$ at the top. The frequency of a quarter-wavelength strip can be determined by using equation (1) [2, 35]. Therefore, the expected fundamental mode resonance of the strip can be predicted. The equivalent (total) length of the strip that made up the ram horn is determined from equation (2). The first term at the RHS of equation (3) denotes the circumference of a circle, while the second term denotes the length of the slit of $i$ th ring:

$$
f_{r} \approx \frac{C_{o}}{4 L_{t} \sqrt{\left(\varepsilon_{r}+1\right) / 2}}
$$

where

$$
L_{t}=L_{R_{1}}+L_{R_{2}}
$$

and

$$
L_{R_{i}}=2 \pi r_{i}-S_{i}, \quad \text { for } i=1 \text { and } 2,
$$

where

$$
\begin{aligned}
& S_{i}=\frac{\left(\theta-\varphi_{i}\right) \times 2 \pi r_{i}}{\theta} \\
& r_{i}=R_{i}+w_{r} .
\end{aligned}
$$

The AMF width $\left(w_{f}\right)$ is calculated using the standard microstrip line equations (5)-(9) $[35,36]$ :

$$
\begin{array}{ll}
Z_{0}= \begin{cases}\frac{120 \pi}{\sqrt{\varepsilon_{e f f}}\left\{w_{f} / h+1.393+0.677 \ln \left(w_{f} / h+1.444\right)\right\}}, & \text { for } \frac{w_{f}}{h} \leq 1, \\
\frac{60}{\sqrt{\varepsilon_{e f f}}} \ln \left(\frac{8 h}{w_{f}}+\frac{w_{f}}{4 h}\right), & \text { for } \frac{w_{f}}{h} \geq 1,\end{cases} \\
\varepsilon_{\text {eff }}=\frac{\varepsilon_{r}+1}{2}+\frac{\varepsilon_{r}-1}{2}\left(\frac{1}{\sqrt{1+12\left(h / w_{f}\right)}}\right) . &
\end{array}
$$

Since the value of the characteristic impedance is known in this case to be $50 \Omega$, the width of the microstrip line can be calculated using 


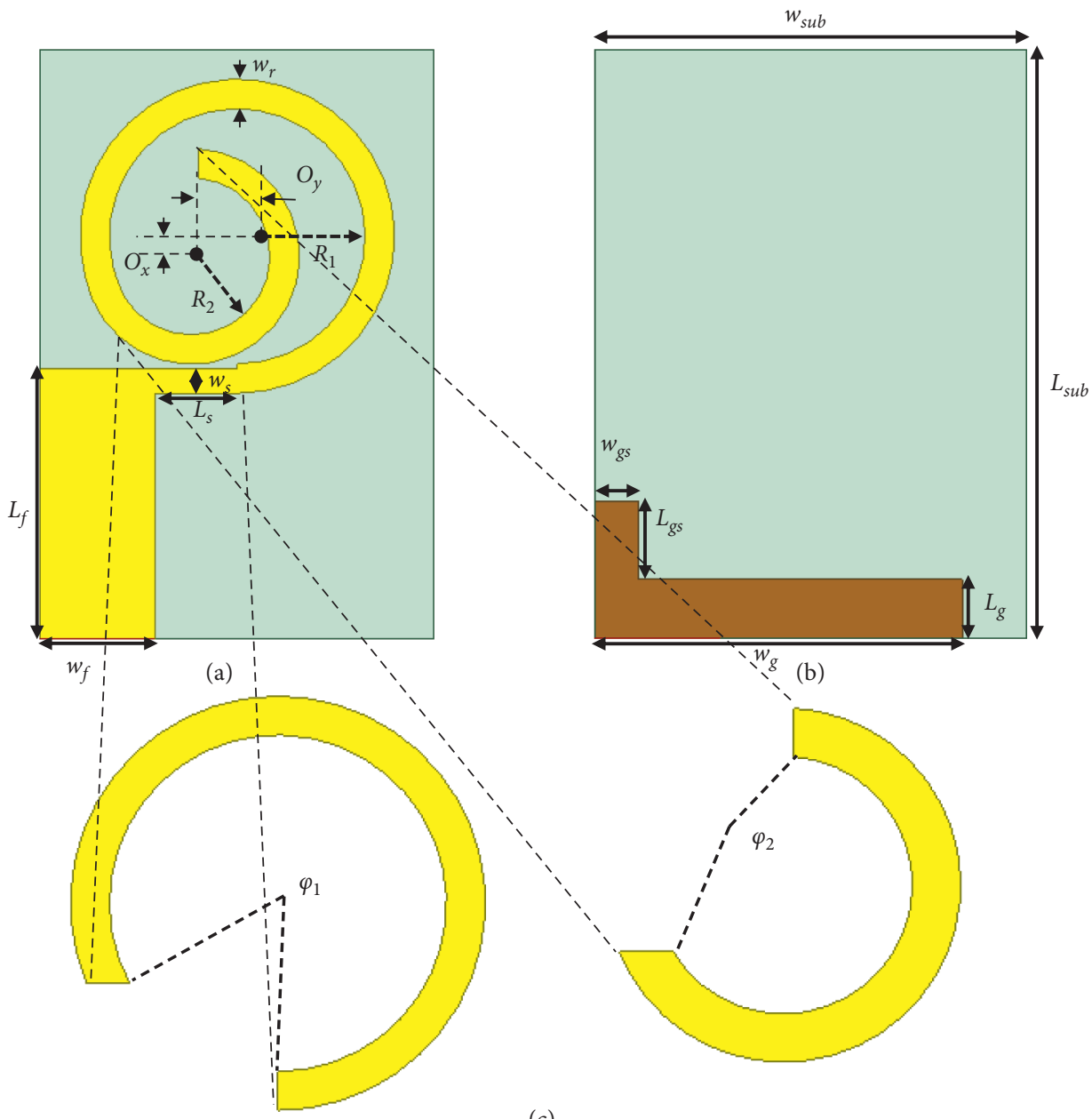

(c)

FIGURE 1: Configuration of the proposed ram horn-like folded antenna: (a) top view, (b) bottom-view, and (c) concatenated slit rings.

TABLE 1: Optimized design parameter of the proposed ram horn-like folded antenna, $\varphi_{1}=241.9^{\circ}$ and $\varphi_{2}=170.1^{\circ}$.

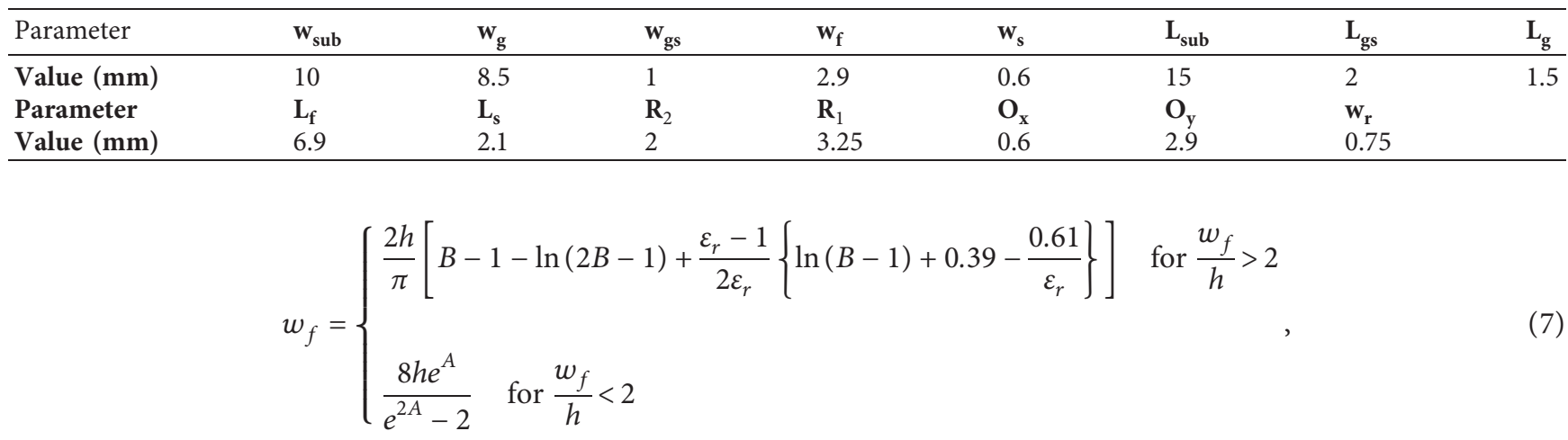

where

$$
\begin{aligned}
& A=\frac{Z_{0}}{60} \sqrt{\frac{\varepsilon_{r}+1}{2}}+\frac{\varepsilon_{r}-1}{\varepsilon_{r}+1}\left(0.23+\frac{0.11}{\varepsilon_{r}}\right), \\
& B=\frac{377 \pi}{2 Z_{0} \sqrt{\varepsilon_{r}}},
\end{aligned}
$$

where $L_{t}$ is the equivalent length of the unfolded strip, $L_{R_{i}}$ is the length of the $i$ th arc-strip, $S_{i}$ is the arc gap of the $i$ th ring, $R_{i}$ is the inner radius of the $i$ th ring, $\varphi_{i}$ is the angle subtended by $i$ th $\operatorname{arc}, w_{f}$ is the width of the microstrip feedline, $h$ is the thickness of the dielectric, $Z_{0}$ is the line characteristic impedance $(50 \Omega), \varepsilon_{r}$ is the permittivity of the substrate, and $\varepsilon_{\text {eff }}$ is the effective permittivity. 


\section{Results and Discussion}

3.1. Reflection Coefficient (S11). The fabrication of the prototype of the proposed ram horn-like folded antenna is shown in Figure 2, which demonstrates the practicability of the proposed antenna radiating patch shape. Figure 3 shows the measured and simulated $S_{11}$ results of the antenna proposed in this work. It can be observed that, for both simulated and measured results, two modes are excited which implies that the proposed antenna is a dual-band antenna. It can be observed that, for simulation, the two resonances are $2.3 \mathrm{GHz}$ and $5.7 \mathrm{GHz}$ with a $-10 \mathrm{~dB}$ bandwidth of $70 \mathrm{MHz}$ and $481 \mathrm{MHz}$ and a return loss of $15.42 \mathrm{~dB}$ and $17.6 \mathrm{~dB}$, respectively. It can be observed that there is a shift toward the lower frequency, while the resonance at the upper frequency of the measured $S 11$ is maintained. That is, the measured resonances are $2.3 \mathrm{GHz}(2.298 \mathrm{GHz})$ and $5.8 \mathrm{GHz}$, respectively. It can also be observed that the measured $-10 \mathrm{~dB}$ bandwidth is $100 \mathrm{MHz}$ and $820 \mathrm{MHz}$ at lower and upper bands, respectively. In terms of return loss, the measured reflection coefficient at the lower and the upper bands is $13.3 \mathrm{~dB}$ and $23.36 \mathrm{~dB}$, respectively. The variation in the results could be traced to the effect of cable and connector losses as well as the fabrication errors. It can be deduced that this antenna can be used in WiMAX and $5 \mathrm{GHz}$ band WLAN applications. In other to study the effect of the ground plane and its protruding stub, the parametric study is done and presented in the next section.

3.2. Parametric Study. The parametric study of the proposed ram horn-inspired shape antenna is carried out to understand the impact of some design parameters and justify the optimized values of the parameter presented in Table 1 . The parametric study specifically focused on the ground plane effect on the resonance behavior of the antenna proposed.

3.2.1. Effect of $w_{g}$. Figure 4 shows the effect of $w_{g}$ on the resonance behavior of the proposed antenna. It can be observed that an increase in the value of $w_{g}$ leads to a tunning effect towards lower frequency at the upper band. It can also be noticed that, as $w_{g}$ increases from $6 \mathrm{~mm}$, aside from shifting the resonant frequency downward, the impedance matching is also enhanced until $7 \mathrm{~mm}$ after which the reflection coefficient starts increasing. $5.8 \mathrm{GHz}$ is the desired frequency at the upper band; therefore, $8.5 \mathrm{~mm}$ is taken as the optimized value of $g_{w}$ in the proposed configuration. It can also be observed that variation in $w_{g}$ has no significant frequency tunning effect at the lower band, but it has a pronounced effect on its impedance matching, as shown in Figure 4. The tunning and impedance matching effect of $w_{g}$ is more pronounced at the upper band of the proposed ram horn-like folded antenna than at the lower band. Conclusively, $g_{w}$ can be used to both tune the upper band resonant frequency as well as the impedance matching of both lower and upper bands.

3.2.2. Effect of $L_{g}$. As can be seen in Figure $5, L_{g}$ significantly affects the impedance matching of the proposed ram horn- like folded antenna at both bands. It can be observed that as $L_{g}$ increases, the reflection coefficient increases which implies that $1 \mathrm{~mm}$ has the best impedance matching at both frequency bands as shown in Figure 5. Nonetheless, to ensure good ground plane support for the proposed antenna, $1.5 \mathrm{~mm}$ has been taken as the optimized value in the proposed configuration. As can be noticed from Figure 5, the highest suitable length of the ground plane to achieve a $10 \mathrm{~dB}$ return loss in both frequency bands is $2 \mathrm{~mm}$. Therefore, ground length has a tremendous effect on the impedance matching of the proposed structure at both frequencies.

3.2.3. Effect of $\mathbf{L}_{\mathrm{gs}}$. Figure 6 shows how $\mathrm{S}_{11}$ changes with $L_{\mathrm{gs}}$. It can be observed that an increase in $L_{\text {gs }}$ not only reduces the impedance matching at both bands but also results in frequency tunning at the upper band. As shown in Figure 6, to ensure a $10 \mathrm{~dB}$ return loss at the lower band, the maximum value of $L_{\mathrm{gs}}$ should be $4 \mathrm{~mm}$. Although $1 \mathrm{~mm}$ has the best impedance matching at the upper band, it does not have the best $S_{11}$ at the lower band. Therefore, for a reasonable reflection coefficient at both resonant frequencies, $2 \mathrm{~mm}$ is choosen as the optimal value in this paper.

3.2.4. Effect of $\mathbf{w}_{\mathrm{gs}} \cdot w_{\mathrm{gs}}$ does not have a significant effect on the resonant frequency of the proposed antenna, but a small variation can be seen in the reflection coefficient of the antenna as it increases. Although $0.5 \mathrm{~mm}$ has the best $S_{11}$ at both frequencies, this is more pronounced at the lower band as can be seen in Figure 7. It can be observed that $1 \mathrm{~mm}$ has a comparative $S_{11}$ with $0.5 \mathrm{~mm}$ at both resonant frequencies. Besides, to avoid significant fabrication error and to further enhance the ground plane support of the proposed antenna, $1 \mathrm{~mm}$ was chosen as the optimized value in the proposed configuration.

3.3. Radiation Pattern, Gain, and Radiation Efficiency. As shown in Figure 8(a), the radiation pattern at E-plane and $\mathrm{H}$-plane is bidirectional and omnidirectional, respectively, at $2.3 \mathrm{GHz}$ with a peak of $-1.5 \mathrm{~dB}$ at $10^{\circ}$ and a $3 \mathrm{~dB}$ beamwidth of $70^{\circ}$. The E-plane and $\mathrm{H}$-plane radiation pattern at $5.8 \mathrm{GHz}$ is a dumbbell and omnidirectional pattern, respectively, with a peak of $2.36 \mathrm{~dB}$ at $180^{\circ}$ and a $3 \mathrm{~dB}$ beamwidth of $130^{\circ}$, as shown in Figure 8(b). As shown in Figure 9, a peak gain of $0.62 \mathrm{dBi}$ and $2.2 \mathrm{dBi}$ is achieved at the lower and upper bands, respectively. The peak efficiency at the lower and the upper band is $93.67 \%$ and $99.87 \%$, respectively, as shown in Figure 9. With this analysis, the ram horn-like folded antenna proposed shows an acceptable performance despite its compactness.

3.4. Current Distribution. To understand the mode of operation of the proposed antenna, the vector current distributions at the two resonant frequencies are plotted and analyzed. As can be seen in Figure 10(a), a high current concentration is noticed on the folded strip and the feeding branch except at the strip-tip where there is mode cancelation at $2.3 \mathrm{GHz}$. It can also be observed that the ground 


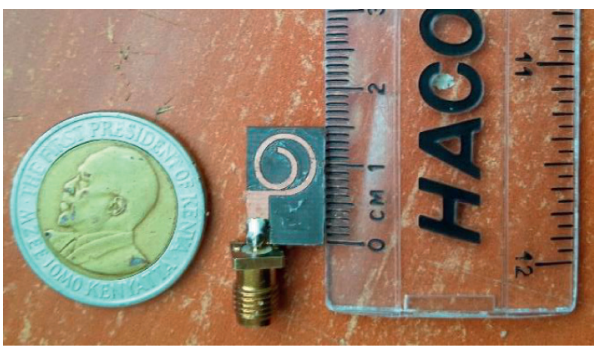

(a)

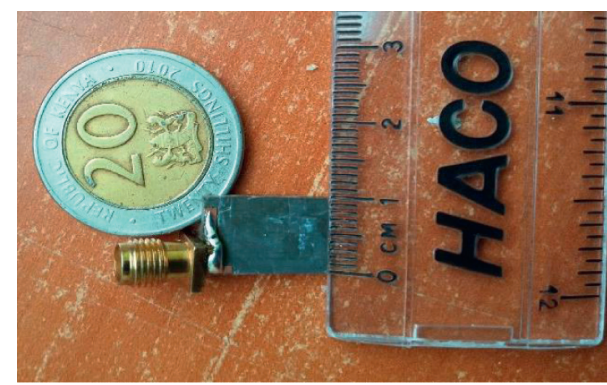

(b)

FIGURE 2: Prototype of the proposed ram horn-like folded antenna. (a) Top view. (b) Ground plane.

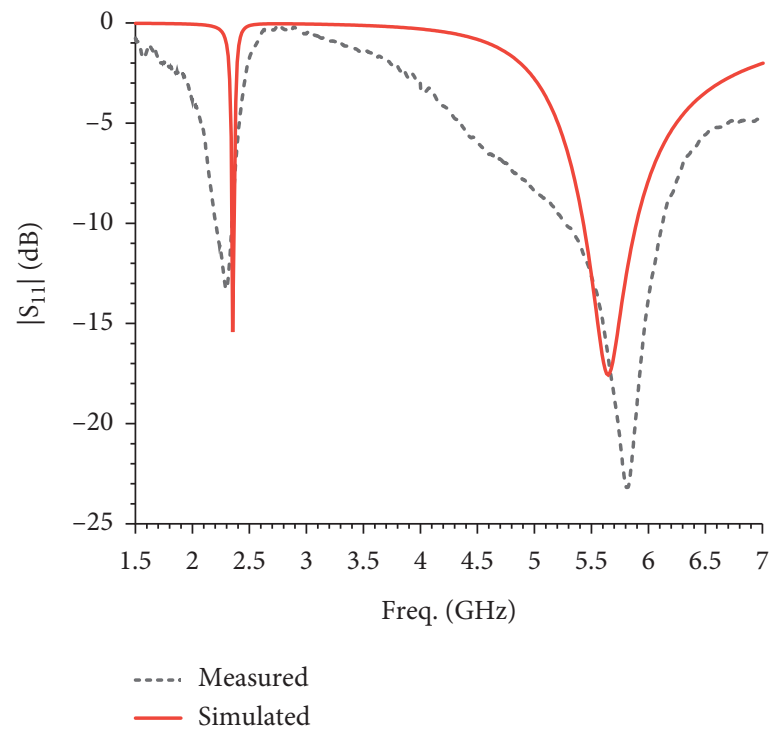

FIGURE 3: Simulated and measured S11 of the proposed ram horn-like folded antenna.

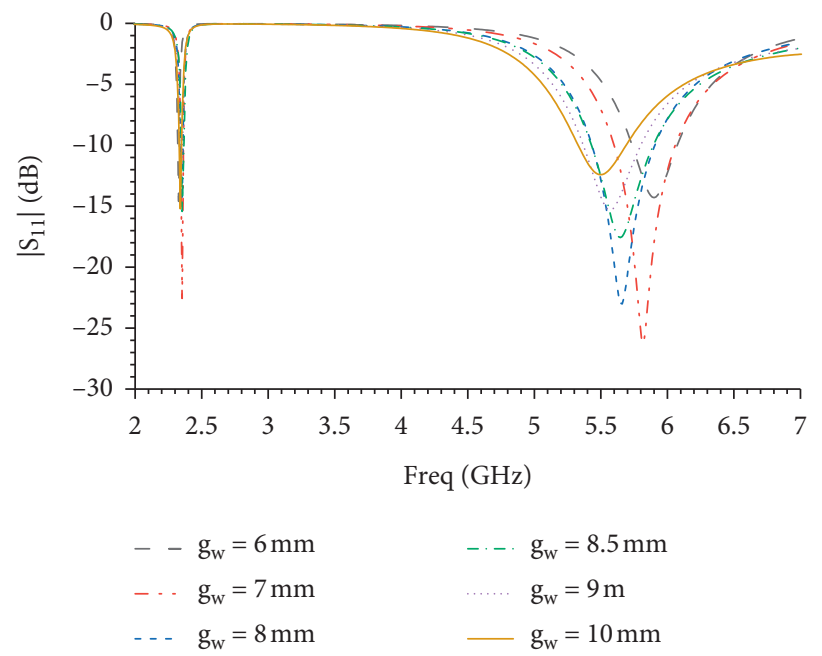

Figure 4: $S_{11}$ variation due to $g_{w}$. 


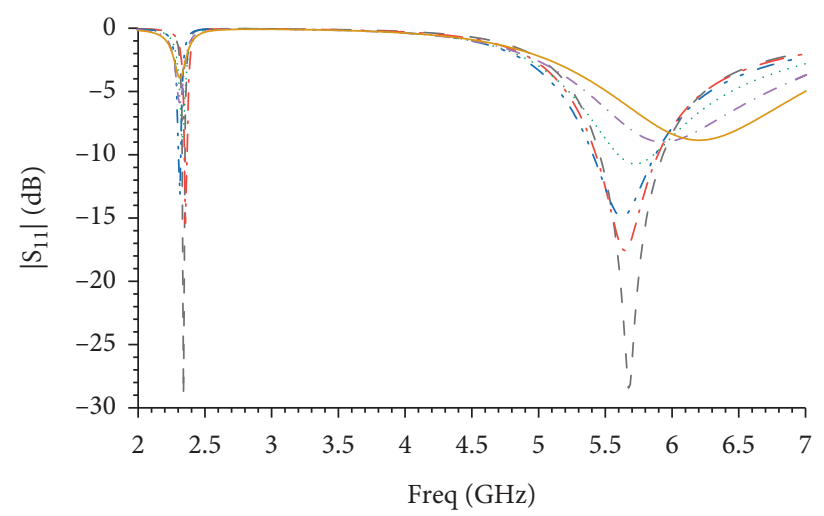

$$
\begin{aligned}
\ldots-\mathrm{L}_{\mathrm{g}}=1 \mathrm{~mm} & \mathrm{~L}_{\mathrm{g}}=3 \mathrm{~mm} \\
\ldots-\mathrm{L}_{\mathrm{g}}=1.5 \mathrm{~mm} & \mathrm{~L}_{\mathrm{g}}=4 \mathrm{~mm} \\
\ldots-\mathrm{L}_{\mathrm{g}}=2 \mathrm{~mm} & \quad \mathrm{~L}_{\mathrm{g}}=5 \mathrm{~mm}
\end{aligned}
$$

Figure 5: S11 variation due to $L_{g}$.

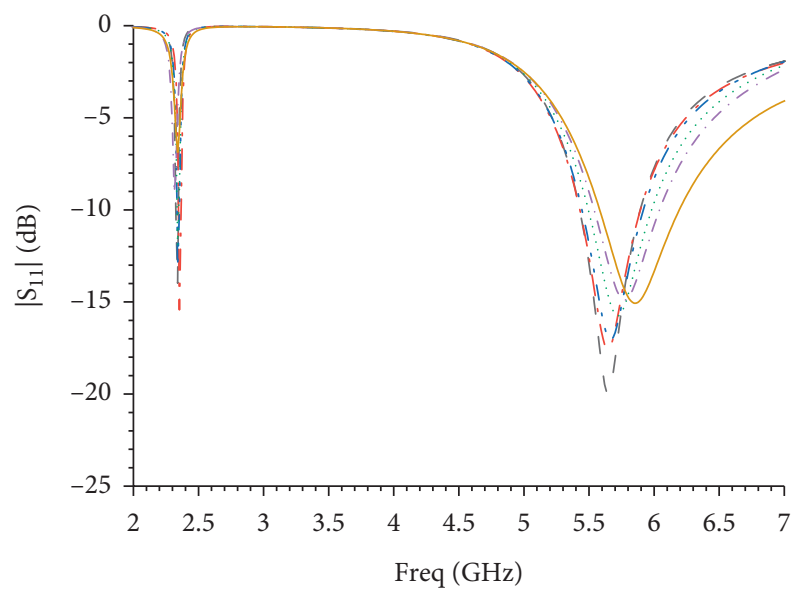

$$
\begin{aligned}
& \text { - - } \mathrm{L}_{\mathrm{gs}}=1 \mathrm{~mm} \\
& \ldots \mathrm{L}_{\mathrm{gs}}=2 \mathrm{~mm} \\
& \text { _.. } \mathrm{L}_{\mathrm{gs}}=3 \mathrm{~mm} \\
& \mathrm{~L}_{\mathrm{gs}}=4 \mathrm{~mm} \\
& \text { … } \mathrm{L}_{\mathrm{gs}}=5 \mathrm{~mm} \\
& \mathrm{~L}_{\mathrm{gs}}=6 \mathrm{~mm}
\end{aligned}
$$

FIgURE 6: S11 variation due to $L_{\mathrm{gs}}$.

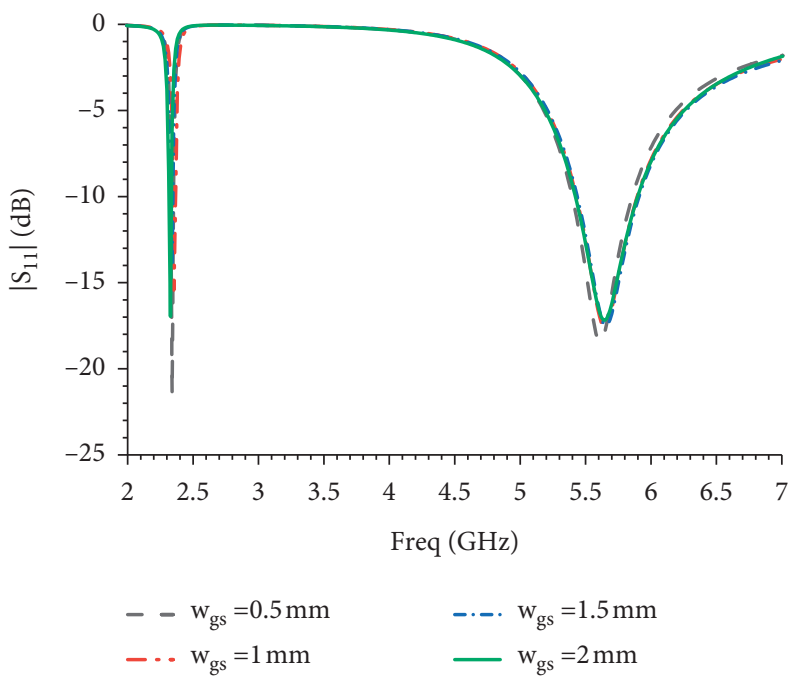

FIgURE 7: S11 variation due to $w_{\text {gs }}$. 


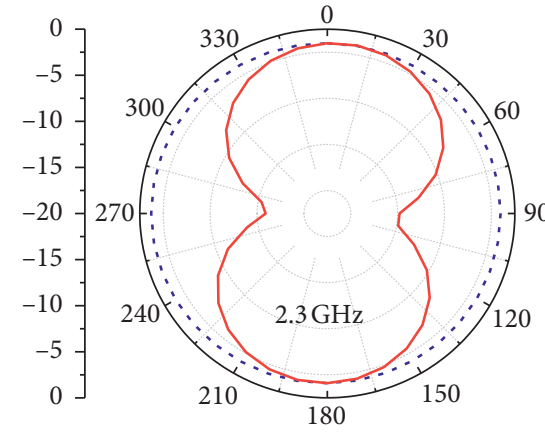

(a)

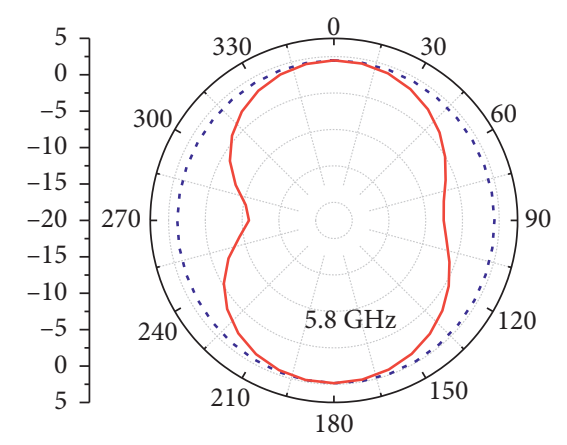

(b)

Figure 8: $2 \mathrm{D}$ radiation pattern of the ram horn-like folded antenna.

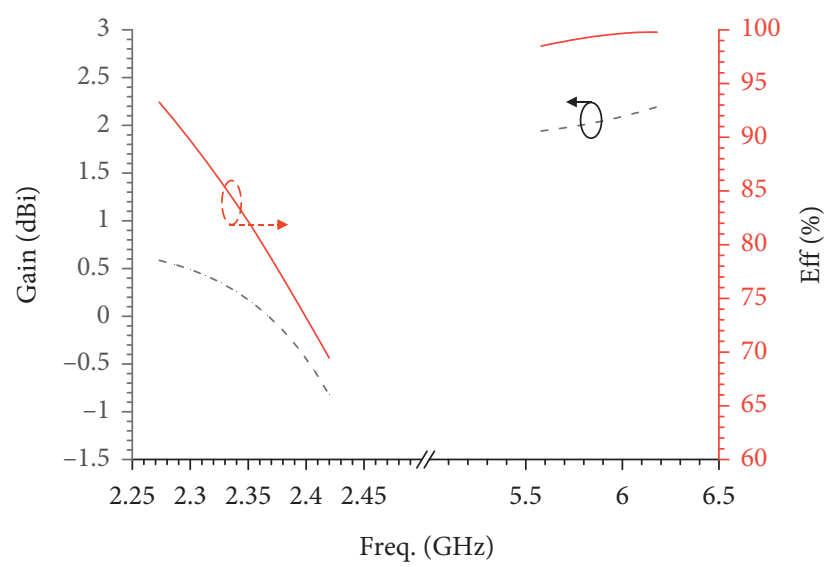

FIGURE 9: Gain and efficiency of the ram horn-like folded antenna proposed.

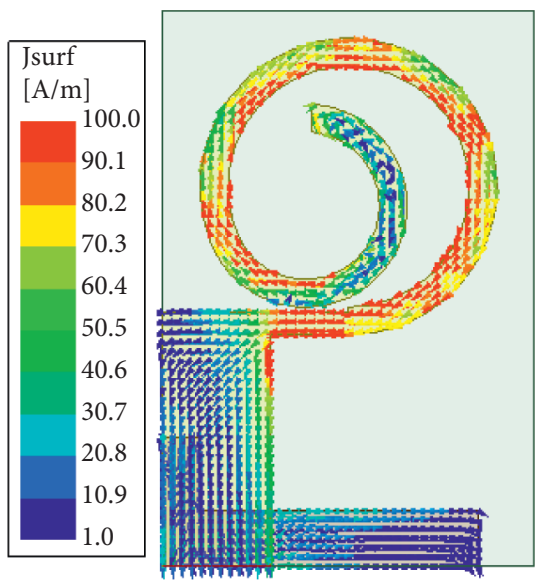

(a)

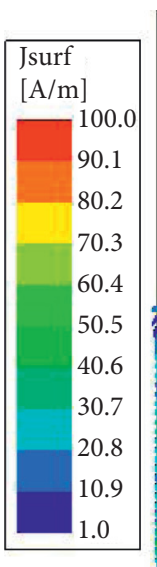

.

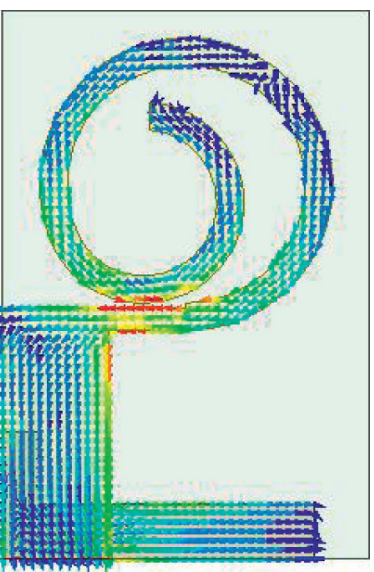

(b)

FIgURE 10: Vector current distribution of the proposed ram horn-like folded antenna: (a) $2.3 \mathrm{GHz}$ and (b) $5.8 \mathrm{GHz}$.

plane does not contribute much to the resonant frequency at 2.3 GHz. These validate the fundamental mode frequency predicted by equation (1) and the results of the parametric study. At $5.8 \mathrm{GHz}$, a high current concentration is observed around the feedline-branch strip and some part of the folded strip. It can also be observed in Figure 10(b) that there is a 
TABLE 2: Comparison of the ram horn-like folded antenna with recent works.

\begin{tabular}{|c|c|c|c|c|c|c|}
\hline Ref & Size $\left(\lambda_{\mathbf{g}}^{2}\right)$ & Freq. $(\mathrm{GHz})$ & Gain & Eff. (\%) & Approach & Complexity \\
\hline$[6]$ & $0.70 \times 0.70$ & $2.5 / 4.2 / 5.5 / 6.8$ & $0.5-4.5 \mathrm{dBi}^{+}$ & $84 / 90 / 89 / 96$ & Meandering and DGS & High \\
\hline$[12]$ & $0.50 \times 0.52$ & $2.4 / 3.5$ & $2.25 / 0.88(\mathrm{dBi})$ & $76 / 85$ & Metamaterial & High \\
\hline [13] & $0.44 \times 0.49$ & $\begin{array}{c}1.22 / 1.57 / 2.45 / \\
3.42\end{array}$ & $1.75 / 3 / 6 / 3(\mathrm{dBi})$ & $73 / 63 / 86 / 57$ & Multiple slots & High \\
\hline [15] & $0.55 \times 0.35$ & 4.0 & $5.1 \mathrm{dBi}$ & 71.6 & Metasurface & High \\
\hline [23] & $0.38 \times 0.38$ & $\begin{array}{c}2.23 / 3.49 / 5.48 / \\
7.48\end{array}$ & $7.85 \mathrm{dBi}^{*}$ & NR & Balloon and rectangular & High \\
\hline$[10]$ & $0.41 \times 0.19$ & $2.5 / 5.4$ & $2.23 / 3.48 \mathrm{~dB}$ & $97.2 / 99.9$ & Semileaf shaped with slit & High \\
\hline [26] & $0.73 \times 0.25$ & $0.9 / 1.95 / 5.8$ & $3.2 / 3.8 / 9.2 \mathrm{dBi}$ & $67-95$ & Folded branch with slit & High \\
\hline [32] & $0.42 \times 0.77$ & $0.85 / 1.8 / 2.6$ & $10 \mathrm{~dB}^{\#}$ & $60-90^{+}$ & Folded monopole with SRR & Medium \\
\hline [33] & $0.22 \times 0.20$ & $\begin{array}{c}1.575 / 2.9 / 3.5 / 4.8 / \\
5.5\end{array}$ & $\begin{array}{c}2.2 / 2.8 / 3.2 / 4.5 / \\
4.4 \mathrm{dBi}\end{array}$ & $50 / 78 / 84 / 92 / 94$ & Loaded IFA with Via & High \\
\hline [36] & $0.38 \times 0.42$ & $2.48 / 3.49$ & $2.4 / 3.5(\mathrm{~dB})$ & NR & Meandering, SSR, and CPW & High \\
\hline [37] & $0.95 \times 0.95$ & 3.39 & $4.15 \mathrm{dBic}$ & 87.32 & R-DRA, aperture coupled & High \\
\hline [38] & $0.26 \times 0.17$ & $1.22 / 6.06$ & 0.99/3.72 dBi & $57 / 91.8$ & CRLH-TL and CPW & High \\
\hline [39] & $0.31 \times 0.14$ & $2.5 / 3.35 / 5.7$ & $1.7 / 1.5 / 2.05$ & $81.1 / 79.6 / 81.5$ & Multiple resonator & High \\
\hline$[40]$ & $0.35 \times 0.35$ & $3.3 / 5.01 / 7.46 / 9.48$ & $0.4 / 0.28 / 4.19 / 2.05$ & $\begin{array}{c}46.6 / 50.8 / 72.2 / \\
50.9\end{array}$ & Metamaterial & High \\
\hline$[41]$ & $0.42 \times 0.49$ & $3.59 / 5.53^{+}$ & $3 / 3.6 \mathrm{dBi}$ & $93 / 87$ & C-SRR, H-CRR, and ACGP & Medium \\
\hline$[42]$ & $0.96 \times 0.56$ & $\begin{array}{c}1.45 / 2.45 / 3.85 / \\
5.13 / 5.8\end{array}$ & $2.7 / 4.8 / 4.1 / 2.5 / 4.2$ & NR & Window grille shape & High \\
\hline $\begin{array}{l}\text { This } \\
\text { work }\end{array}$ & $0.11 \times 0.17$ & $2.3 / 5.8$ & $0.62 / 2.2 \mathrm{dBi}^{*}$ & $93.67 / 99.87^{*}$ & $\begin{array}{c}\text { Ram horn shaped, AMF, ground } \\
\text { protruding stub }\end{array}$ & Medium \\
\hline
\end{tabular}

${ }^{*}$ peak value; ${ }^{+}$range; ${ }^{\#}$ diversity gain; ${ }^{+}$extracted from the comparative table; NR, not reported; C-SRR, circular split ring resonator; H-CRR, hexagonal closed ring resonator; ACGP, asymmetric coplanar ground plane; CRLH-TL, composite right-/left-handed transmission line; R-DRA, rectangular-dielectric resonator antenna; SSR, square split ring; MTM, metamaterial; DGS, defected ground structure; CPW, coplanar waveguide.

significant current around the edge of the ground plane which shows that the ground plane plays an important role in the resonance at the upper band. This is in agreement with the parametric study presented before.

\section{Comparative Study}

To validate the compactness of the ram horn-like folded antenna proposed in this work, a comparative analysis along with the recently published works is carried out and presented in Table 2. Guided wavelength size at the lowest resonant frequency has been used for normalization purposes. It can be observed that the proposed antenna is comparatively compact than the recently reported works in literature. It can also be observed that the proposed antenna shows competitive performance in terms of size, gain, and efficiency when compared with the recent works, as shown in Table 2.

\section{Conclusion}

A compact ram horn-like folded dual-band antenna for LTE-A and WLAN applications is proposed in this work. The proposed antenna design is based on a folded monopole, partial ground, AMF, and protruding stub. The overall antenna footprint is $15 \times 10 \mathrm{~mm}^{2}$, and it operates at $2.3 \mathrm{GHz}$ and $5.8 \mathrm{GHz}$ with a gain of $0.62 \mathrm{dBi}$ and $2.2 \mathrm{dBi}$, and radiation efficiency of $93.67 \%$ and $99.87 \%$, respectively. The comparative analysis of the antenna proposed in this work with the state of the art shows that the proposed antenna is the smallest yet maintaining good radiation characteristics.
Therefore, the antenna proposed in this work is a competitive candidate for future portable wireless communication.

\section{Data Availability}

The data supporting the findings of this study are all presented within the article.

\section{Conflicts of Interest}

There are no conflicts of interest among the authors.

\section{Acknowledgments}

This work was sponsored and supported by the African Union through the Pan African University Institute of Basic Sciences, Technology, and Innovation.

\section{References}

[1] W.-Y. Chiang, C.-H. Ku, C.-A. Chen et al., "A power-efficient multiband planar USB dongle antenna for wireless sensor networks," Sensors, vol. 19, no. 11, Article ID 2568, 2019.

[2] J. O. Abolade, D. B. O. Konditi, and V. M. Dharmadhikary, "Compact hexa-band bio-inspired antenna using asymmetric microstrip feeding technique for wireless applications," Heliyon, vol. 7, no. 2, Article ID e06247, 2021.

[3] B. Fady, J. Terhzaz, A. Tribak, and F. Riouch, "Integrated miniature multiband Antenna designed for WWD and SAR assessment for human exposure," International Journal of Antennas and Propagation, vol. 2021, Article ID 5548834, 15 pages, 2021. 
[4] M. Alibakhshikenari, B. S. Virdee, A. Ali, and E. Limiti, "Extended aperture miniature antenna based on CRLH metamaterials for wireless communication systems operating over UHF to C-band," Radio Science, vol. 53, no. 2, pp. 154-165, 2018.

[5] F. Majeed and D. V. Thiel, "An Optimized circuit in plastic meander line antenna for $2.45 \mathrm{GHz}$ applications," International Journal of Antennas and Propagation, vol. 2016, Article ID 7398567, 7 pages, 2016.

[6] R. Patel, T. Upadhyaya, A. Desai, and M. Palandoken, "Low profile multiband meander antenna for LTE/WiMAX/WLAN and INSAT-C application," AEU - International Journal of Electronics and Communications, vol. 102, pp. 90-98, 2019.

[7] T. K. Das, B. Dwivedy, and S. K. Behera, "Design of a meandered line microstrip antenna with a slotted ground plane for RFID applications," AEU-International Journal of Electronics and Communications, vol. 118, Article ID 153130, 2020.

[8] S. Bhaskar and A. K. Singh, "Meandered cross-shaped slot circularly polarised antenna for handheld UHF RFID reader," $A E U$ - International Journal of Electronics and Communications, vol. 100, pp. 106-113, 2019.

[9] C. Y. Cheung, J. S. M. Yuen, and S. W. Y. Mung, "Miniaturized printed inverted-f antenna for internet of things: a design on PCB with a meandering line and shorting strip," International Journal of Antennas and Propagation, vol. 2018, Article ID 5172960, 5 pages, 2018.

[10] J. O. Abolade, D. B. O. Konditi, and V. M. Dharmadhikary, "Ultra-compact hexa-band bio-inspired antenna for 2G, 3G, $4 \mathrm{G}$ and $5 \mathrm{G}$ wireless applications," International Journal on Communications Antenna and Propagation, vol. 11, no. 3, pp. 1-13, 2021.

[11] M. Alibakhshikenari, B. S. Virdee, L. Azpilicueta et al., "A comprehensive survey of "metamaterial transmission-line based antennas: design, challenges, and applications"," IEEE Access, vol. 8, pp. 144778-144808, 2020.

[12] M. Hasan, M. Rahman, M. Faruque, M. Islam, and M. Khandaker, "Electrically compact srr-loaded metamaterial inspired quad band antenna for bluetooth/wifi/wlan/wimax system," Electronics, vol. 8, no. 7, pp. 790-7, 2019.

[13] B. B. Q. Elias, P. J. Soh, A. A. Al-Hadi, R. Joshi, Y. Li, and S. K. Podilchak, "Design of a quad band CPW-fed compact flexible patch antenna for wearable applications," in Proceedings of the 2020 14th European Conference on Antennas and Propagation (EuCAP), pp. 1-5, Copenhagen, Denmark, March 2020.

[14] M. Mehrparvar and F. Hodjat Kashani, "Microstrip antenna miniaturization using metamaterial structures," in Proceedings of the 20th Iranian Conference on Electrical Engineering (ICEE2012), pp. 1243-1246, Tehran, Iran, May 2012.

[15] H. L. Zhu, S. W. Cheung, and T. I. Yuk, "Miniaturization of patch antenna using metasurface," Microwave and Optical Technology Letters, vol. 57, no. 9, pp. 2050-2056, 2015.

[16] A. Kumar, "A compact H-shaped slot triple-band microstrip antenna for WLAN and WiMAX applications," in Proceedings of the 2016 IEEE Annual India Conference (INDICON), pp. 1-4, Bangalore, India, December 2016.

[17] M. Moosazadeh and S. Kharkovsky, "Compact and small planar monopole antenna with symmetrical L- and U-shaped slots for WLAN/WiMAX applications," IEEE Antennas and Wireless Propagation Letters, vol. 13, pp. 388-391, 2014.

[18] N. Dakhli and F. Choubani, "Multiband L-shaped slot antenna loaded with split ring resonator," in Proceedings of the 2020 International Wireless Communications and Mobile
Computing (IWCMC), pp. 1087-1090, Limassol, Cyprus, June 2020.

[19] N. Hamizah Muhamad Mokhtar, N. A. Malek, A. Z. Jusoh, K. Ali, F. Nadia Mohd Isa, and F. Diyana Abdul Rahman, "Design and comparison of printed antennas using meander line technique," Bulletin of Electrical Engineering and Informatics, vol. 8, no. 2, pp. 596-603, 2019.

[20] B. K. Subhash, K. Abhishek, A. Tanweer, S. H. Bharathi, and R. C. Biradar, "A compact audi-shaped slotted multiband Antenna for WiMAX/WLAN/X-band Applications," in Proceedings of the 2018 Second International Conference on Advances in Electronics, Computers and Communications (ICAECC), pp. 1-6, Bangalore, India, February 2018.

[21] K. D. Prasad, T. Ali, and R. C. Biradar, "A compact slotted multiband antenna for L-band and WLAN applications," in Proceedings of the 2017 2nd IEEE International Conference on Recent Trends in Electronics, Information and Communication Technology (RTEICT), pp. 820-823, Bangalore, India, May 2017.

[22] Z. Yu, J. Yu, X. Ran, and C. Zhu, "A novel ancient coin-like fractal multiband Antenna for wireless applications," International Journal of Antennas and Propagation, vol. 2017, pp. 1-10, 2017.

[23] M. Sharma, "Design and analysis of multiband Antenna for bluetooth, WiMAX, WLAN and X-band downlink applications," in Proceedings of the 2019 9th International Conference on Cloud Computing, Data Science and Engineering (Confluence), pp. 130-133, Noida, Uttar Pradesh, January 2019.

[24] O. A. Fakolujo and J. Abolade, "Quad-band microstrip patch antenna based on dual-cross slots," International Journal of Scientific Research and Engineering Development, vol. 2, no. 5, pp. 1-5, 2019.

[25] J. O. Abolade, D. B. O. Konditi, and V. M. Dharmadhikary, “A comparative study of compact multiband bio-inspired asymmetric microstrip fed antennas (BioAs-MPAs) for wireless applications," Journal of Engineering, vol. 2021, no. 3, 17 pages, Article ID 6676689, 2021.

[26] W. Hu, X. Liu, S. Gao et al., "Compact wideband folded dipole antenna with multi-resonant modes," IEEE Transactions on Antennas and Propagation, vol. 67, no. 11, pp. 6789-6799, 2019.

[27] J. Cui, A. Zhang, and X. Chen, "An omnidirectional multiband Antenna for railway application," IEEE Antennas and Wireless Propagation Letters, vol. 19, no. 1, pp. 54-58, 2020.

[28] J. R. Panda and R. S. Kshetrimayum, "A printed 2.4 GHz/5.8 $\mathrm{GHz}$ dual-band monopole antenna for WLAN and RFID applications with a protruding stub in the ground plane," in Proceedings of the 2011 National Conference on Communications (NCC), pp. 1-5, Bangalore India, January 2011.

[29] Z. Yang, Y. Cui, X. Mo, and R. Li, "A wideband crossed-dipole antenna for lte700/gsm850/gsm900 base stations," in Proceedings of the 2019 IEEE-APS Topical Conference on Antennas and Propagation in Wireless Communications (APWC), pp. 30-33, Granada, Spain, September 2019.

[30] Z. Tang, J. Liu, R. Lian, Y. Li, and Y. Yin, "Wideband differentially fed dual-polarized planar antenna and its array with high common-mode suppression," IEEE Transactions on Antennas and Propagation, vol. 67, no. 1, pp. 131-139, 2019.

[31] H. Liu, B. Lu, and L. Li, "Novel miniaturized octaband Antenna for LTE smart handset applications," International Journal of Antennas and Propagation, vol. 2015, pp. 1-8, 2015.

[32] B. Souny and C. Morlaas, "Usage of characteristic modes with specific boundary conditions for wideband Antenna design: application to a cage loaded monopole antenna," IEEE 
Transactions on Antennas and Propagation, vol. 66, no. 8, pp. 3819-3829, 2018.

[33] S. S. Alja'Afreh, Q. Xu, L. Xing, Y. Huang, C. Song, and E. Almajali, "A dual-element folded strip monopole with SRR loading for multiband handset MIMO applications," in Proceedings of the 2020 14th European Conference on Antennas and Propagation (EuCAP), pp. 1-5, Copenhagen, Denmark, March 2020.

[34] A. Chatterjee, M. Midya, L. P. Mishra, and M. Mitra, "Branch line strip loaded compact printed inverted-F antenna (IFA) for penta-band applications," AEU - International Journal of Electronics and Communications, vol. 124, Article ID 153340, 2020.

[35] Y. Huang and K. Boyle, Antennas: From Theory To Practice, John Wiley \& Sons, Chichester, West Sussex, UK, 2nd ed. edition, 2008.

[36] R. Garg, P. Bhartia, I. J. Bahl, and A. Ittipiboon, Microstrip Antenna Design Handbook, Artech House, Norwood, MA, USA, 2001.

[37] K. Kumar Naik, "Asymmetric CPW-fed SRR patch antenna for WLAN/WiMAX applications," AEU - International Journal of Electronics and Communications, vol. 93, pp. 103-108, 2018.

[38] R. Kumar, S. R. Thummaluru, and R. K. Chaudhary, "Improvements in wi-MAX reception: a new dual-mode wideband circularly polarized dielectric resonator antenna," IEEE Antennas and Propagation Magazine, vol. 61, no. 1, pp. 41-49, 2019.

[39] R. Sonak, M. Ameen, and R. K. Chaudhary, "CPW-fed electrically small open-ended zeroth order resonating metamaterial antenna with dual-band features for GPS/WiMAX/ WLAN applications," AEU-International Journal of Electronics and Communications, vol. 104, pp. 99-107, 2019.

[40] J. Kulkarni and C.-Y.-D. Sim, "Low-profile, compact multiband monopole antenna for futuristic wireless applications," in Proceedings of the 2020 IEEE International Conference on Electronics, Computing and Communication Technologies (CONECCT), pp. 1-5, Bangalore, India, July 2020.

[41] Y. V. Bhasakar Reddy, A. M. Prasad, and K. V. Swamy, "Metamaterial inspired compact penta-band Antenna for wiMAX, WLAN, satellite band and X-band Applications," in Proceedings of the 2020 IEEE International Conference on Electronics, Computing and Communication Technologies (CONECCT), pp. 1-6, Bangalore, India, July 2020.

[42] M. Ameen, A. Mishra, and R. K. Chaudhary, "Asymmetric CPW-fed electrically small metamaterial- inspired wideband antenna for 3.3/3.5/5.5 GHz WiMAX and 5.2/5.8 GHz WLAN applications," AEU - International Journal of Electronics and Communications, vol. 119, Article ID 153177, 2020.

[43] Z. Yu, Y. Li, Z. Lin, and X. Ran, "Design of window grille shape-based multiband Antenna for mobile terminals," International Journal of Antennas and Propagation, vol. 2021, pp. 1-14, Article ID 6684959, 2021. 